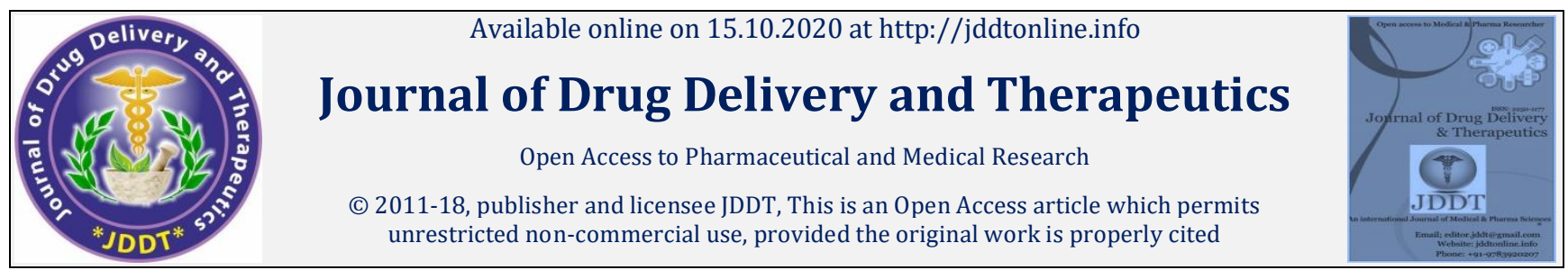

Open Access

Review Article

\title{
Rheumatoid Arthritis: Etiology, Treatment and Animal Models
}

\author{
Chaudhary Archana*, Pandit Vinay \\ Department of Pharmaceutics, Laureate Institute of Pharmacy, Kathog, H.P., India
}

\begin{abstract}
Rheumatoid arthritis is an autoimmune disease that can cause joint pain and damage throughout your body. About $75 \%$ of Rheumatoid arthritis patients are women. In fact, $1-3 \%$ of women may get rheumatoid arthritis in their lifetime. The disease most often begins between the ages of 30 and 50. Rheumatoid arthritis occurs when your immune system attacks the synovium, the lining of the membranes that surround your joints. The resulting inflammation thickens the synovium, which can eventually destroy the cartilage and bone within the joint. The tendons and ligaments that hold the joint together weaken and stretch. Gradually, the joint loses its shape and alignment. It also affects other organs of body like: skin, eyes, heart, kidneys, and lungs. The main risk factors that cause Rheumatoid arthritis are Age, Gender, Genetics, weight, smoking, diet, etc. Three main ways to treat rheumatoid arthritis are Drugs, physical therapies and surgery. There are four main groups of drugs that are used to treat rheumatoid arthritis are non-steroidal anti-inflammatory drugs, disease-modifying anti-rheumatic drugs and steroids (also known as corticosteroids). Collagen induced arthritis and Adjuvant arthritis are the most commonly used standard animal models in Rheumatoid arthritis. This literature review assessed the sign \& symptoms, risk factors, etiology, treatment and standard animal models for Rheumatoid arthritis.
\end{abstract}

Keywords: Rheumatoid arthritis, Inflammation, Antirheumatic drugs, Adjuvants, Rat, Mice.

Article Info: Received 17 Aug 2020; Review Completed 24 Sep 2020; Accepted 06 Oct 2020; Available online 15 Oct 2020

Cite this article as:

Chaudhary A, Pandit V, Rheumatoid Arthritis: Etiology, Treatment and Animal Models, Journal of Drug Delivery and Therapeutics. 2020; 10(5-s):290-298 http://dx.doi.org/10.22270/jddt.v10i5-s.4357

*Address for Correspondence:

Chaudhary Archana, Department of Pharmaceutics, Laureate Institute of Pharmacy, Kathog, H.P., India

\section{Introduction:}

In Rheumatoid arthritis "Rheumatoid" means musculoskeletal illness, "arthr" means joint and" it is" means inflammation. Rheumatoid arthritis (RA) is an autoimmune disease which causes chronic inflammation of joints and other organs too (like liver, lungs, skin, eyes, kidney, blood vessels, etc.).1,2 The major symptoms of RA are: Pain, Swelling, Stiffness and the minor symptoms are fatigue, Weight loss, Sweating, Chest pain, Dry eyes, Loss of appetite. ${ }^{3}$

Animal disease models have proven to be invaluable tool to reveal the pathophysiological pathways of inflammatory arthritis, and for investigational testing of therapeutic agents. Rat and mice are the most commonly utilized animal species. Animals are used either as strains (spontaneously develop arthritis) or as inducible models (in which disease can be provoked by administration of arthritogenic stimuli). ${ }^{4}$ The first animal model for Rheumatoid Arthritis was adjuvant induced arthritis models in rats and introduced by an intradermal injection of mycobacterial cell wall suspended in the mineral oil. This model was proven to be inadequate due to systemic acute inflammation in suffering animals. New model developed which contain bacteria and oil compounds and resemble RA criteria is the pristane induced arthritis model. It is useful for the drug validation of in t-cell mediated pathways. The most commonly method used is type-II collagen induced arthritis. It is induced by immunizing various cartilage proteins to attack on the joints. The standard models used for RA are adjuvant induced models, collagen induced arthritis. ${ }^{5}$

\section{Risk factor that can increase RA 6,7}

There are number of genetic and environmental factors that increase the risk of developing RA:

a) Age: RA can occur at any stage but mostly seen in the middle age persons.

b) Gender: Women get more affected by RA as compare to men.

c) Genetic susceptibility or Family History: There is an increased risk of RA, if any member of the family has suffered with RA.

d) Obesity: People who are overweight especially women appear to be at a somewhat higher risk of developing RA.

e) Environmental factors: People after getting exposed to something in the environment like cigarette smoke or a specific pathogen like a bacteria that lives in the intestines get the chances of RA

\section{Etiology:}

A healthy joint (Fig. No.1) typically has two bones covered with articular cartilage at the ends. Articular cartilage is a 
type of connective tissue that acts like a protective cushion a lubricated surface for bones to smoothly glide against. One type of joint, like the knee joint is called a synovial joint. A synovial joint connects two bones with a fibrous joint capsule that is continuous with the periosteum or outer layer of both bones. The fibrous capsule is lined with a synovial membrane that has cells that produce synovial fluid and remove debris. The synovial fluid is normally a viscous fluid like the jelly-like part of a chicken egg and it helps lubricate the joint. To help serve these synovial cells, the synovial membrane also has blood vessels and lymphatic's running through it. Together, the synovial membrane and the articular cartilage form the inner lining of the joint space. 8,9, 10

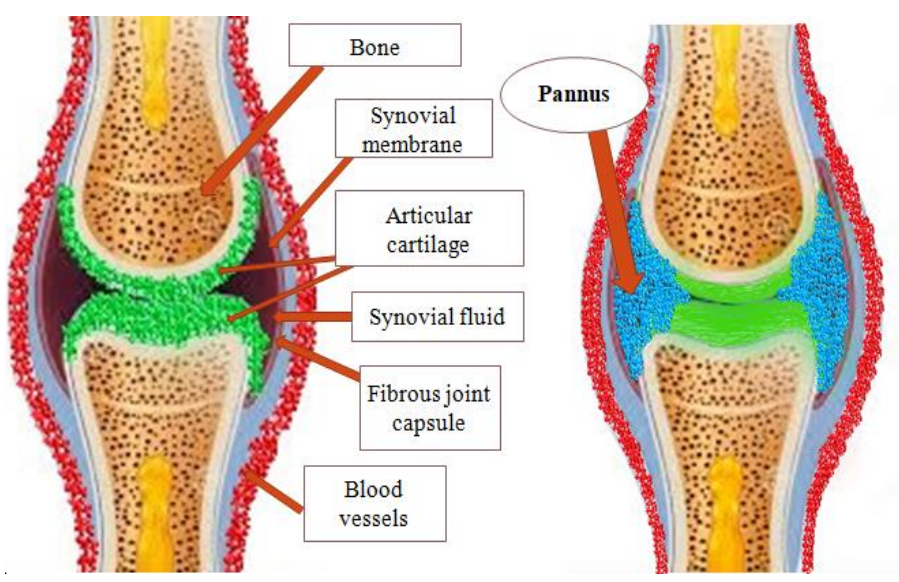

Figure 1: Healthy Joint and Joint with Pannus formation

Rheumatoid arthritis is an autoimmune process that is typically triggered by an interaction between a genetic factor and the environment. For example, (Fig. No. 2) a person with a certain gene for an immune protein like human leukocyte antigen, or HLA- DR1 and HLA-DR4, might develop rheumatoid arthritis after getting exposed to something in the environment like cigarette smoke or a specific pathogen like a bacteria that lives in the intestines. These environmental factors can cause modification of our own antigens, such as IgG antibodies or other proteins like Type- II collagen or vimentin. Type- II collagen and vimentin can get modified through a process called Citrullination. That's when the amino acid Arginine found in these proteins is converted into another amino acid, Citrulline. Meanwhile, due to the susceptibility genes HLA- DR1 and HLA-DR4, immune cells sometimes are not "clever" enough, so they get confused by these changes and they no longer recognize these proteins as self-antigens. The antigens get picked up by antigen- presenting cells, and get carried to the lymph nodes to activate CD4+ T-helper cells T-helper cells stimulate the nearby B- cells to start proliferating and differentiate into plasma cells, which produce specific auto antibodies against these self- antigens. In rheumatoid arthritis, $\mathrm{T}$ - helper cells and antibodies enter the circulation and reach the joints. Once there, T- cells secrete cytokines like interferon- $\gamma$ and interleukin- 17, to recruit more inflammatory cells like proteases which break down the proteins in the articular cartilage. Without the protective cartilage, the underlying bones are exposed and can directly rub against one another. In addition, inflammatory cytokines increase a protein on the surface of T- cells, known as RANKL or receptor activator of nuclear factor kappa-B ligand. RANKL allows the T-cells to bind RANK, a protein on the surface of osteoclasts, to get them to start breaking down bone. Meanwhile, antibodies also enter the joint space. One antibody is called rheumatoid factor, or RF, which is an IgM antibody that targets the constant Fc domain of altered IgG antibodies. Another antibody is anti-cyclic citrullinated peptide antibody, or CCP, which targets citrullinated proteins. When these antibodies bind to their targets, they form immune complexes which accumulate in the synovial fluid. There, they activate the complement system, a family of 9 small proteins that work in an enzymatic cascade to promote joint inflammation and injury. Finally, the chronic inflammation causes angiogenesis, or the formation of new blood vessels around the joint, which allows even more inflammatory cells to arrive. As the disease progresses, multiple joints on both sides of the body get inflamed and gradually destroyed. Macrophages, into the joint space. Macrophages will also produce inflammatory cytokines, like tumor necrosis factor, or TNF- $\alpha$, interleukin- 1 and interleukin- 6, which together with the T-cell's cytokines, stimulate synovial cells to proliferate. The increase in synovial cells and immune cells creates a Pannus, which is a thick, swollen synovial membrane with granulation or scar tissue, made up of fibroblasts, myofibroblasts and inflammatory cells. Over time, the Pannus can damage cartilage and other soft tissues and also erode bone. Activated synovial cells also secrete. $8,9,10,11$

\section{Effect of RA on other organs of body: ${ }^{12,13}$}

Inflammatory cytokines stay temporarily within the tight joint space and after some time they escape through the bloodstream and reach the multiple organ systems causing various extra-articular problems as discussed below:

Brain: Interleukin -1 or -6 travels to the brain, where they act as pyrogens, inducing fever.

Skeletal muscle: In skeletal muscle, they promote protein breakdown.

Skin: In Skin it lead to the formation of rheumatoid nodules, which are round- shaped collections of macrophages and lymphocytes with a central area of necrosis, or tissue death.

Blood vessels: Blood vessels also get affected. Their walls get inflamed, resulting in various forms of vasculitis and make them prone to developing atheromatous or fibro fatty plaques.

Liver: In response to inflammatory cytokines, the liver also starts producing high amounts of hepcidin, a protein that decreases the serum iron levels by inhibiting its absorption by the gut and trapping it into macrophages or liver cells.

Lung: Between the lung interstitium fibroblasts get activated and proliferate, causing fibrotic or scar tissue that makes it harder for the alveolar gas exchange, while also the pleural cavities surrounding the lungs can get inflamed, filling up with 
fluid, known as pleural effusion, and this can sometimes mess with lung expansion.

\section{Diagnosis of rheumatoid arthritis: ${ }^{13}$}

RA is diagnosed by reviewing symptoms, conducting a physical examination, and by X-rays and lab tests. It's best to diagnose RA earliest as its symptoms appear so that proper treatment started to slow or stop disease progression.
Diagnosis and effective treatments, particularly treatment to suppress or control inflammation, can help reduce the damaging effects of RA. There is no single test that shows whether you have RA. Rheumatoid arthritis is diagnosed from a combination of things, including: location and symmetry of painful joints, especially the hand joints, joint stiffness in the morning, Bumps and nodules under the skin (rheumatoid nodules). Diagnosis of RA is done by using following ways:

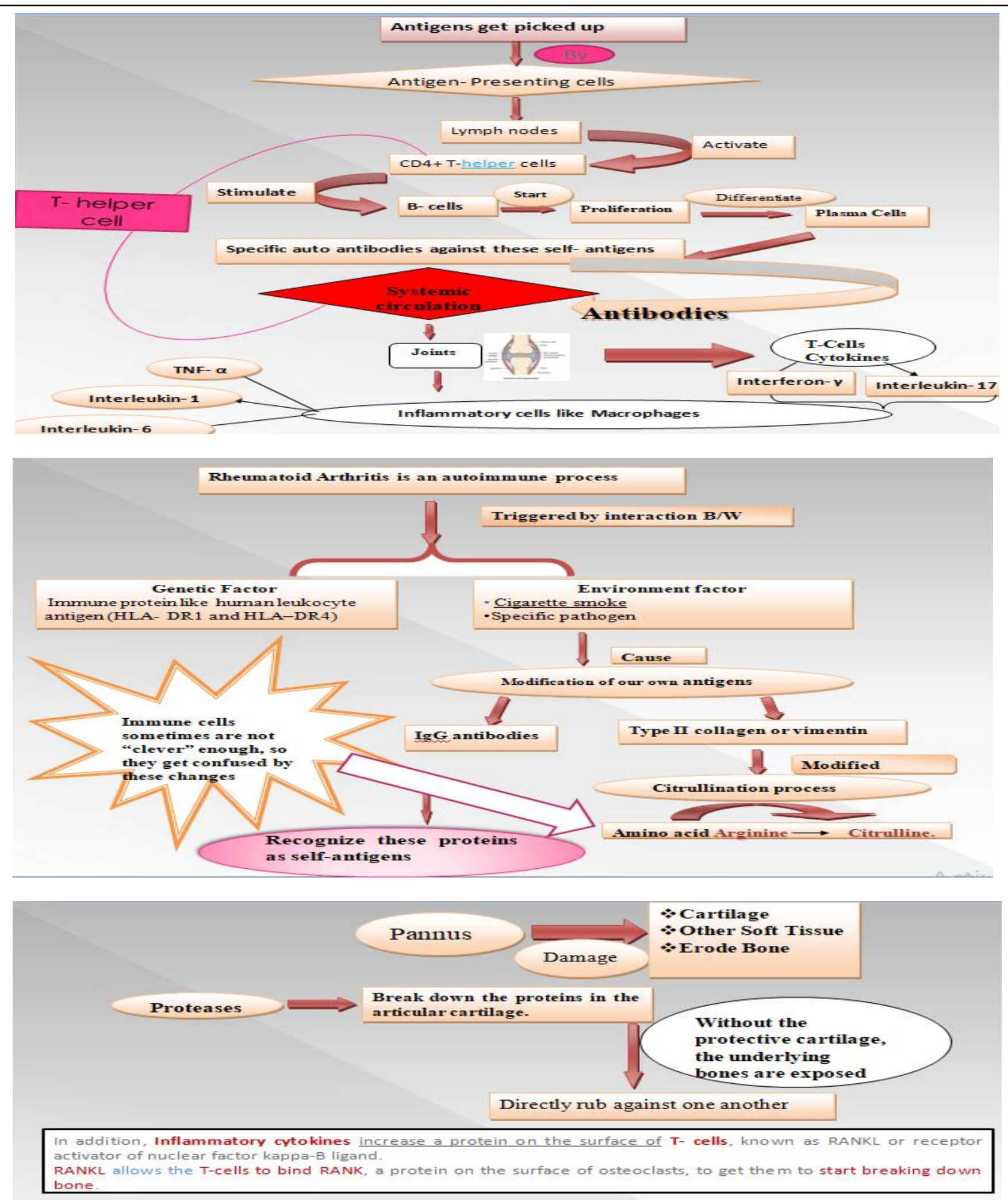

Figure 2: Etiology of Rheumatoid Arthritis 
A) Blood tests: It is analyzed for the presence of:

a) Rheumatoid factor

b) Anti-citrullinated peptide antibody

c) Erythrocyte sedimentation rate (ESR): A high erythrocyte sedimentation rate may indicate inflammation in your joints.

d) C-reactive protein (CRP): This protein may also indicate inflammation in your joints.

e) Complete blood count (CBC): This includes hemoglobin and hematocrit tests, which may reveal anemia. This may also be associated with RA.

B) Imaging studies: Imaging studies such as X- ray usually reveal decreased bone density around affected joints, soft tissue swelling, narrowing of the joint space, and bony erosions.

\section{Treatment for RA: ${ }^{13,14}$}

RA can be effectively treated and managed with medications and self-management strategies. There are three main ways to treat rheumatoid arthritis:

1. Drugs

2. Physical therapies

3. Surgery

Drugs:

Disease modifying antirheumatic drugs (DMARDs)

\section{A. Nonbiological drugs}

1. Immunosuppressants: Methotrexate, Azathioprine, Cyclosporine

2. Sulfasalazine

3. Chloroquine or Hydroxychloroquine

4. Leflunomide

B. Biological agents

1. TNF $\alpha$ inhibitors: Etanercept, Infliximab, Adalimumab

\section{IL-1 antagonist: Anakinra}

4. Adjuvant drugs

Corticosteroids: Prednisolone and others (Gold and penicillamine are obsolete DMARDs)

Surgery: It may include:

1. Joint Replacement

2. Arthrodesis

3. Synovectomy

Physiotherapy:

1. Passive Treatments for Rheumatoid Arthritis:

a) Cold therapy: Reduces circulation, which ultimately decreases swelling.

b) Heat therapy: Eases muscle tension and gets blood to flow more quickly to the painful area.

c) Hydrotherapy: Involves reducing your RA-related pain and other symptoms with water. With hydrotherapy, you will be submerged in warm water to relieve your symptoms.

d) Massage: It can help reduce muscle tension and promote good circulation.

e) Transcutaneous electrical nerve stimulation: It works by blocking pain signals from getting to your spinal cord. It also helps decrease muscle spasms.

f) Ultrasound: It creates warmth using sound waves, which enhances circulation and decreases joint pain, inflammation, and stiffness.

\section{Active Treatments for Rheumatoid Arthritis:}

a) Flexibility and strengthening exercises: Improve your range of motion and help you build muscle strength. Yoga and Pilates are flexibility and strengthening exercises.

b) Low-impact aerobic exercise: It is gentle but effective at helping you manage rheumatoid arthritis symptoms. Light walking is an example of this type of exercise.

\section{Animal models used for RA:}

The use of animals for scientific purposes is both a longstanding practice in biological research and medicine. The remarkable anatomical and physiological similarities between humans and animals, particularly mammals, have prompted researchers to investigate a large range of mechanisms and assess novel therapies in animal models before applying their discoveries to humans. ${ }^{15}$

Selection criteria for animal models used for the study are based on: 16

i. Smallest animal species

ii. Strains specific characteristics desirable to require for the specific study there proposed (resemblance)

iii. Lower Cost

iv. Mortality rate

v. Find Commercial vendors (easily availability)

There are various types of models used for RA but the standard models used for RA are : ${ }^{15,16}$

a) Adjuvant arthritis

b) Collagen Induced Arthritis

c) Arthus reaction

\section{Adjuvant arthritis:}

Adjuvant induced arthritis is developed by immunizing the rat with the complete freund's adjuvant containing Mycobacterium tuberculosis or Mycobacterium butyricum or Staphylococcus epidermidis. This model has been widely used as a model for Rheumatoid arthritis. ${ }^{18,19}$

Mechanism: Mycobacterium cell wall membrane contains peptidoglycan which contains muramyl dipeptide. Muramyl dipeptide activates macrophages and cytokine production increases which in turn activates Beta cell and T-cells (MHC), it leads to RA in rats. 6,20

\section{Requirements:20,22,23}

1. Adjuvant: Complete freund's adjuvant is composed of mycobacteria and oil 
a) Type of oil: Different types of oils such as olive oil, mineral oil, squalane, liquid paraffin can be used for inducing RA in Rat strains.

\section{b) Heat killed bacteria:}

Different strains of heat killed mycobacterium are used to isolate peptidoglycans and muramyl dipeptide. Peptidoglycans and muramyl dipeptide can be used as antigens for inducing adjuvant induced arthritis. Particle size and concentration of suspension plays a major role in inducing RA more effectively. If the particle size of the suspension is smaller in size, it will show effective arthritogenic response in rats as compare to large particle size. Appropriate concentration of suspension is used to effectively induce the arthritis $5 \mathrm{mg} / \mathrm{ml}$ of heat killed mycobacterium is suspended in incomplete freund's adjuvant.

Table 1: Commonly used rat strains are

\begin{tabular}{|c|c|}
\hline Rat Strains & Response \\
\hline Lewis & \multirow[t]{3}{*}{ High } \\
\hline Wistar & \\
\hline Brown Norway & \\
\hline Buffalo & \multirow[t]{3}{*}{ Low-Medium } \\
\hline Fisher 344 & \\
\hline $\begin{array}{l}\text { Diabetic -resistant subline of } \\
\text { diabetic BB }\end{array}$ & \\
\hline Wistar Furth & Resistant \\
\hline
\end{tabular}

\section{Procedure:23}

- $\quad$ Male Wistar Lewis rats have been mostly used in this study due to high response of this strain.

- Rats with an initial body weight of 130 to $200 \mathrm{~g}$ are used.

- On day 1 , rats are injected into the sub plantar region of the left hind paw with $0.1 \mathrm{ml}$ of complete Freund's adjuvant. Freund's adjuvant consists of $6 \mathrm{mg}$ mycobacterium butyricum suspended in heavy paraffin oil by thoroughly grinding in mortar and pestle to give a concentration of $6 \mathrm{mg} / \mathrm{ml}$.

- On the same day (Day 1) dosing with the test compounds or the standard is started and continued for 12 days.

- Paw volumes of both sides and body weight are recorded on the day of injection, measured plethysmometer.

- On day 5, the paw volume of the injected side is measured again that is the indication of primary lesion and also the influence of therapeutic agents.

- The severity of the induced adjuvant disease is followed by measurement of the non-injected paw (secondary lesions) with a plethysmometer.

- From day 13 to 21 , the animals are not dosed with the test compound or the standard.

- $\quad$ On day 21 , the body weight of rat is determined again and the severity of the secondary lesions is visually evaluated and grades are assigned to the following parameters as discussed in the Table no.2.

Table 2 Parameters for evaluation of activity

\begin{tabular}{|c|c|c|c|}
\hline S. No. & Body Parts & Observations & Grades \\
\hline \multirow[t]{2}{*}{1.} & \multirow[t]{2}{*}{ Ears } & Absence of nodules and redness & 0 \\
\hline & & Presence of nodules and redness. & 1 \\
\hline \multirow[t]{2}{*}{2.} & \multirow[t]{2}{*}{ Nose } & No swelling of connective tissue & 0 \\
\hline & & Intensive swelling of connective tissue & 1 \\
\hline \multirow[t]{2}{*}{3.} & \multirow[t]{2}{*}{ Tail } & Absence of nodules & 0 \\
\hline & & Presence of nodules & 1 \\
\hline \multirow[t]{2}{*}{4.} & \multirow[t]{2}{*}{ Forepaws } & Absence of inflammation & 0 \\
\hline & & Inflammation of at least 1 joint & 1 \\
\hline \multirow[t]{4}{*}{5.} & \multirow[t]{4}{*}{ Hind paws } & Absence of inflammation & 0 \\
\hline & & Slight inflammation & 1 \\
\hline & & Moderate inflammation & 2 \\
\hline & & Marked inflammation & 3 \\
\hline
\end{tabular}




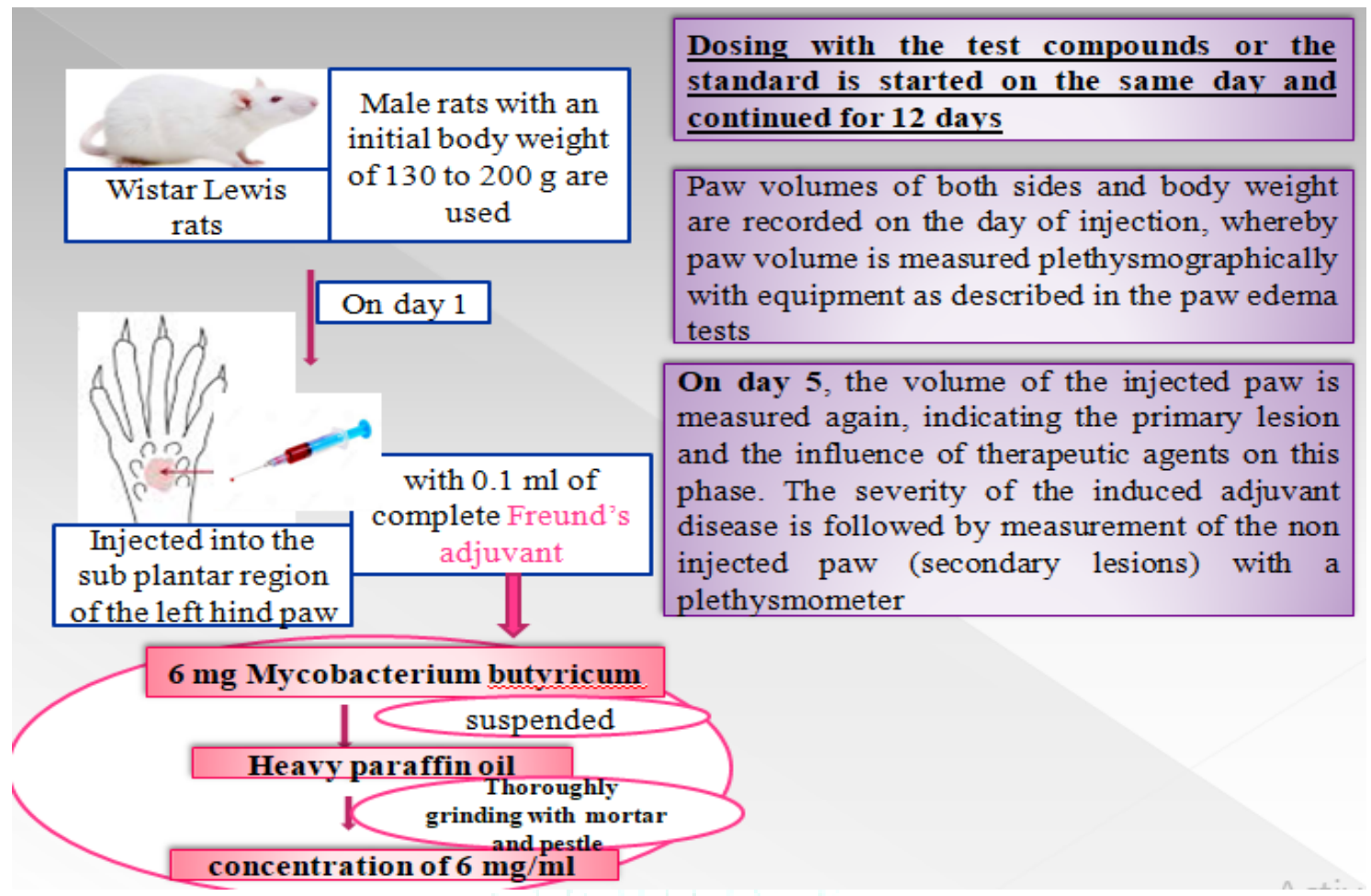

Figure 4: Procedure for inducing Adjuvant arthritis and measurement of test drug on disease

\section{Evaluation:23,25}

\section{Percent inhibition of paw volume:}

a) On day 5(Primary lesions): The percent inhibition of paw volume of the injected left paw over vehicle control is measured.

b) On day 21 (Secondary lesions): The percent inhibition of paw volume of the non-injected right paw over control is measured.

2. Arthritic index: It is calculated as the sum of the score as shown in Table No.2. The average of the treated animals is compared with the control group.

3. Total percentage inhibition: The total percentage change is calculated as:

Total percentage inhibition $=$ Percent inhibition of paw volume on day $5+$ Percent inhibition of non- injected paw on day $21+$ Percent change in arthritic index

\section{Collagen induced Arthritis (CIA):}

It is induced by immunizing the rat through intradermal injection of type II collagen in incomplete Freund's adjuvant. This model is widely used because of the similarities of the symptoms in rats to human disease the test is considered to be useful to detect anti-inflammatory and immunosuppressive properties of test compounds. ${ }^{17,19}$

Mechanism: The demonstration of antibodies to collagen in patients with rheumatic polyarthritis suggests that autoimmunity may contribute to the pathophysiology of synovitis and joint destruction.

\section{Types of type-II collagen:22,23}

Rats susceptibility to collagen induced arthritis is linked to the MHCRT1 locus and varies with the species of type II collagen used for immunization. Porcine type II collagen shows arthritogenic responses whereas type II collagen by bovine being the least arthritogenic.

Table 3: Different strains of the rats showing high response to CIA and different susceptibility of CIA is linked to the MHC types.

\begin{tabular}{|l|l|l|}
\hline S. N. & Strains & MHC RT1 Halotype \\
\hline a) & Wistar & U \\
\hline b) & Sprague-Dawley & F \\
\hline c) & $\begin{array}{l}\text { Bio-breeding (BB)/ } \\
\text { diabetes resistant }\end{array}$ & U \\
\hline d) & Wistar furth & U \\
\hline e) & Louvain & U \\
\hline f) & Osborne-Mendal & U \\
\hline g) & Lewis rats & L \\
\hline
\end{tabular}

\section{Procedure:23}

Bovine Type II collagen is prepared from nasal septum cartilage, which is cut into small fragments, frozen in liquid nitrogen, and pulverized in a freezer mill. Proteoglycan are extracted overnight by stirring $25 \mathrm{~g}$ of pulverized cartilage in 1 liter of $0.2 \mathrm{~N} \mathrm{NaOH}$. Following centrifugation at 20, $000 \mathrm{~g}$ for $30 \mathrm{~min}$, the residue is washed with $250 \mathrm{ml}$ of absolute ethanol, the supernatant aspirated, and the residue vacuum dried. Pepsin (100mg) are added to $150 \mathrm{ml}$ of $0.5 \mathrm{M}$ acetic acid, after which $1.0 \mathrm{~g}$ of cartilage is added to reach a cartilage to pepsin ratio of $10: 1(\mathrm{w} / \mathrm{w})$. The mixture is stirred $18 \mathrm{~h}$ at room temperature and centrifuged at 20000 $\mathrm{g}$ for $1 \mathrm{~h}$. Acid soluble collagen present in the supernatant is precipitated by adding $\mathrm{NaCl}$ to reach a final concentration of $0.9 \mathrm{M}$, followed by centrifugation at $20000 \mathrm{~g}$ for $1 \mathrm{~h}$. The precipitate from $1.0 \mathrm{~g}$ cartilage is dissolved in $100 \mathrm{ml} 1.0 \mathrm{~N}$ $\mathrm{NaCl} / 0.005 \mathrm{M}$ Tris- $\mathrm{HCl}, \mathrm{pH} 7.5$, and stirred for 3 days. Then, 
the solution is dialyzed against $0.02 \mathrm{M} \mathrm{Na} 2 \mathrm{HPO} 4, \mathrm{pH} 9.4$, and the precipitate collected by centrifugation at $30,000 \mathrm{~g}$ for 1 $\mathrm{h}$. The pellet is dissolved in $0.5 \mathrm{M}$ acetic acid, dialyzed against 6 liters of $0.01 \mathrm{M}$ acetic acid, and lyophilized. All procedures, unless otherwise stated are performed at $4{ }^{\circ} \mathrm{C}$.

\section{Test procedure: 23,24}

- Collagen $(2.0 \mathrm{mg} / \mathrm{ml})$ is dissolved in $0.1 \mathrm{M}$ acetic acid and kept overnight stirring at $4{ }^{\circ} \mathrm{C}$.

- Above solution is added dropwise to an equal volume of chilled incomplete Freund's adjuvant.

- Male Wistar rats (6-12) with an initial weight of about $120 \mathrm{~g}$ are used for each group.

- On day 1 , each rat receives a total of $0.5 \mathrm{mg}$ collagen in $0.5 \mathrm{ml}$, equally divided, in 5 sites.
- All injections are intradermally injected one at the base of each appendage and one in the nape of the neck.

- $\quad$ After 7 days post-immunization, the animals receive identical booster injections.

- Control animals receive only the incomplete Freund's adjuvant diluted with $0.1 \mathrm{M}$ acetic acid.

- $\quad$ On day 20, the volume of both hind paws is measured plethysmographically.

- For further testing, only animals with a paw volume of $1.8 \mathrm{ml}$ or greater are used.

- From days 20-40, the animals receive the test compounds (p. o. once a day).

- On day 41, the paw volumes are recorded again.

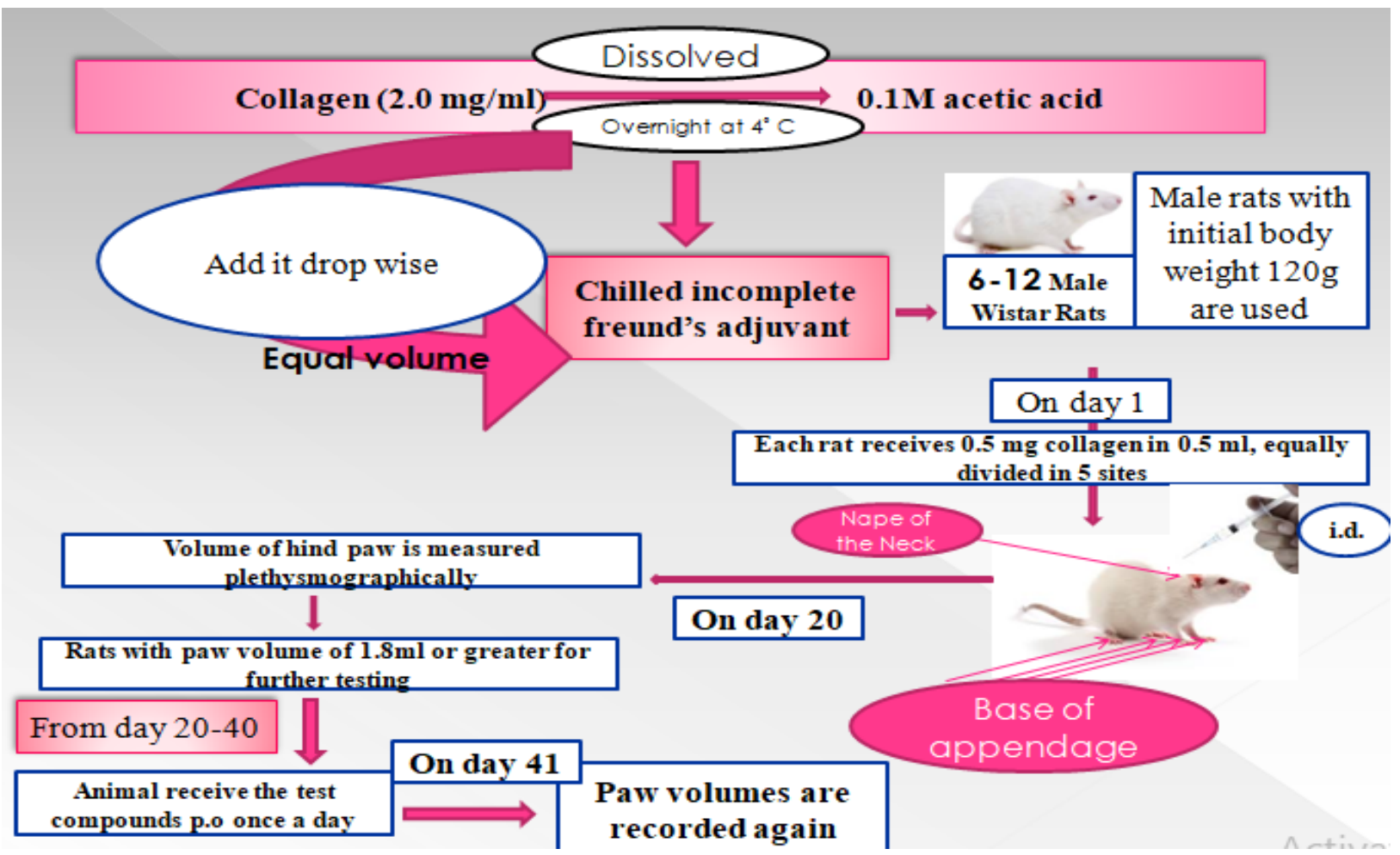

Figure 5: Procedure for inducing Collagen arthritis and measurement of test drug on disease

\section{Evaluation:}

1. Paw volume assessment: The paw volumes of treated animals are recorded plethysmographically. The increase versus day 20 is calculated. The increase is compared with that of controls or animals treated with a standard drug.

2. Arthritic scoring: It is calculated as the sum of the score as indicated in Table No.2 for each animal. ${ }^{23}$

\section{Arthus reaction:}

The immune complex induced arthus reaction comprises inflammatory factors that have been implicated in the acute responses in joints of rheumatic patients. Complement and polymorphonuclear neutrophiles are activated by precipitating antigen-antibody complexes leading to an inflammatory focus characterized by edema, hemorrhage and vasculitis. Arthus reaction of the immediate type becomes maximal after $2-8 \mathrm{~h}$ of its induction. 22

\section{Procedure}

\section{Preparation of Ovalbumin emulsion: 23}

- Ovalbumin (1700 mg) are suspended in paraffin oil $(100 \mathrm{ml})$.

- $\quad$ Pertussis $(4.38 \mathrm{ml}$ ) vaccines are suspended in $70 \mathrm{ml}$ $0.9 \% \mathrm{NaCl}$-solution.

- Above two suspensions are mixed to form an emulsion. 


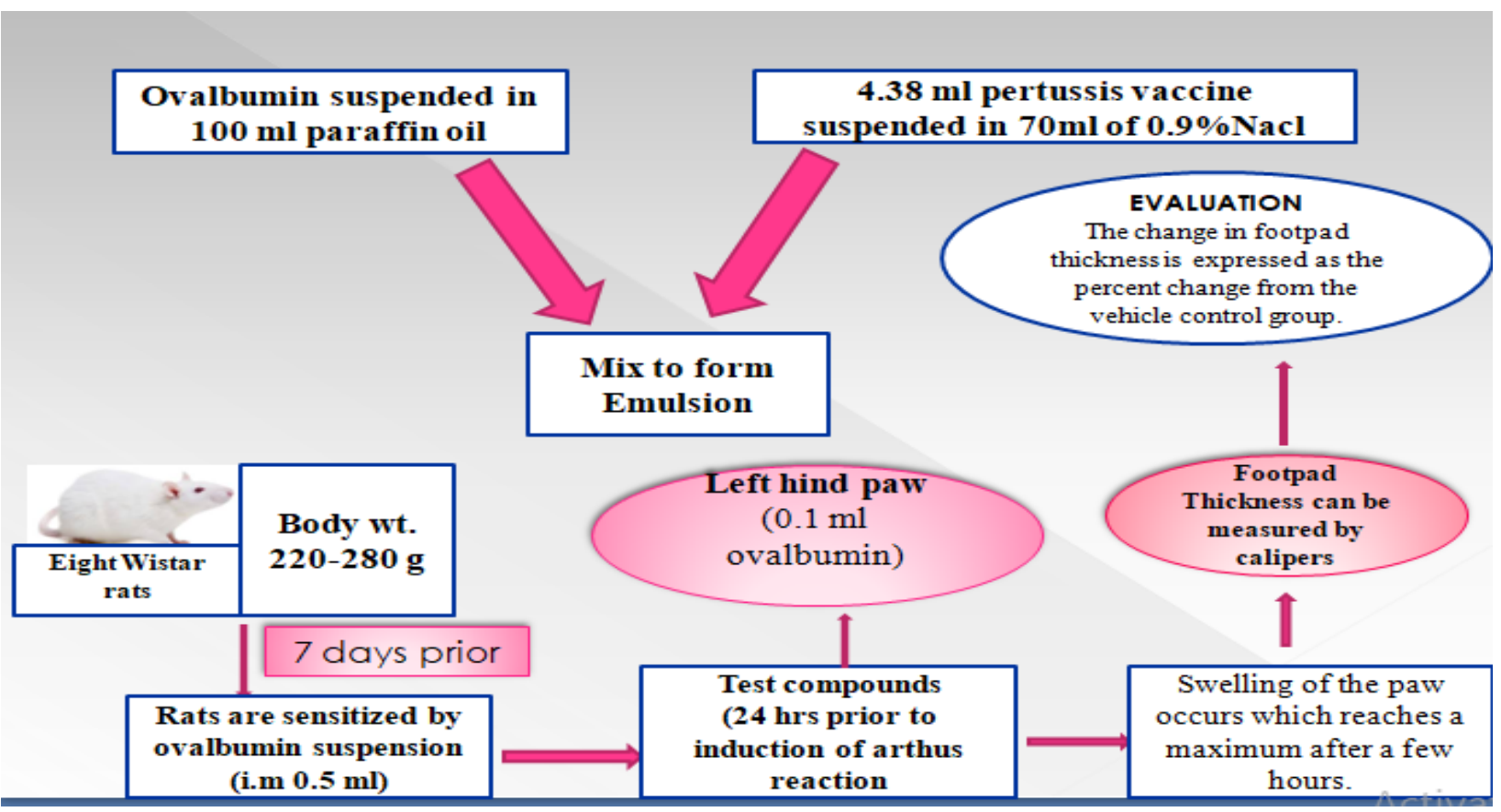

Figure 6: Procedure for inducing Arthus reaction

\section{Test procedure: 23}

- Wistar or Sprague-Dawley rats weighing 220-280 g can be used for the test.

- $\quad$ Rats are intramuscularly sensitized 7 days prior to start of the experiment with ovalbumin suspension $(0.5 \mathrm{ml})$.

- $\quad$ They are housed in groups of eight with standard food and water ad libitum.

- Test compounds are administered to the groups, 24hours and 1 hour prior to induction of the Arthus reaction.

- The rats are injected with ovalbumin $(0.1 \mathrm{ml}$ of $0.04 \%$ solution) in the left hind paw.

- Within few hours swelling of the paw reaches to maximum.

- The footpad thickness can be measured by calipers.

- $\quad$ One group of sensitized animals treated with solvent alone serves as positive control; one group of nonsensitized animals treated with solvent alone serves as negative control.

\section{Evaluation:}

The change in footpad thickness is expressed as the percent change from the vehicle control group. Comparison of experimental group to positive control is evaluated statistically using Student's t-test.

\section{Conclusion:}

In the present review paper discussed about etiology, sign and symptoms and various animal models used for the study of Rheumatoid arthritis. RA is increased with various risk factors associated are: age, gender, genetic susceptibility or family history, obesity, environmental factors, etc. Different organs get affected by RA are: brain, skeletal muscle, skin, blood vessels, liver, lung, etc. There are three main ways to treat rheumatoid arthritis: drugs, physical therapies and surgery, etc. There are various types of models used for RA but the standard models used for RA are: adjuvant arthritis, collagen induced arthritis and arthus reaction.

\section{References:}

1. Sant SM, Suarez TM, Moalli MR, Wu BY, Blaivas M, Laing TJ, Roessler BJ. Molecular lysis of synovial lining cells by in vivo herpes simplex virus-thymidine kinase gene transfer. Human gene therapy. 1998 Dec 10; 9(18):2735-43.

2. El-barbary AM, Khalek MA, Elsalawy AM, Hazaa SM Assessment of lipid peroxidation and antioxidant status in rheumatoid arthritis and osteoarthritis patients. The Egyptian Rheumatologist. 2011 Oct 1; 33(4):179-85.

3. Pincus T, Castrejon I. An evidence-based medical visit for patients with rheumatoid arthritis based on standard, quantitative scientific data from a patient MDHAQ and physician report. Bulletin of the NYU hospital for joint diseases. 2012 Apr 1; 70(2).

4. Fischer BD, Adeyemo A, O'Leary ME, Bottaro A. Animal models of rheumatoid pain: experimental systems and insights. Arthritis research \& therapy. 2017 Dec 1; 19(1):146.

5. Kollias G, Papadaki P, Apparailly F, Vervoordeldonk MJ, Holmdahl R, Baumans V, Desaintes C, Di Santo J, Distler J, Garside P, Hegen M. Animal models for arthritis: innovative tools for prevention and treatment. Annals of the rheumatic diseases. 2011 Aug 1; 70(8):1357-62.

6. Nkemdilim OC. Differential Diagnosis And Tests Of Rheumatoid Arthritis And Its Implication For Physiotherapy.

7. Jordan E, Gallicchio VS. Stem Cell Therapy as a Treatment Method for Rheumatoid Arthritis. Stem Cells Regen Med. 2020; 4(1):1-0.

8. Wright V, Dowson D, Kerr J. The structure of joints. International review of connective tissue research 1973; 6:105-125. Elsevier

9. Kohli N. An investigation of primary human cell sources and clinical scaffolds for articular cartilage repair (Doctoral dissertation, Aston University).

10. Martin JA. Intra-Articular Lubricin Gene Therapy for PostTraumatic Arthritis. University of Iowa Iowa City United States; 2015 Sep 1.

11. Andersson U, Tracey KJ. A new approach to rheumatoid arthritis: treating inflammation with computerized nerve stimulation. InCerebrum: the Dana forum on brain science 2012 Mar (Vol. 2012). Dana Foundation.

12. Ferraz-Amaro I, González-Juanatey C, Lopez-Mejias R, Riancho-Zarrabeitia L, González-Gay MA. Metabolic syndrome in rheumatoid arthritis. Mediators of Inflammation. 2013 Jan 1; 2013. 
13. Iqbal S, Rattu MA. Review of rheumatoid arthritis. US Pharm. 2019; 44(1):8-11.

14. Wasserman A. Diagnosis and management of rheumatoid arthritis. American family physician. 2011 Dec 1; 84(11):1245-52.

15. Andersen ML, Winter LM. Animal models in biological and biomedical research-experimental and ethical concerns. Anais da Academia Brasileira de Ciencias. 2019; 91.

16. Bendele A. Animal models of rheumatoid arthritis. J Musculoskelet Neuronal Interact. 2001 Jun 1; 1(4):377-85.

17. Sindhu RK, Sood N, Puri V, Arora S. Various animal models for preclinical testing of anti-inflammatory agents. International Journal of Pharmaceutical Sciences and Research. 2017 Apr 1; 8(4):1550.

18. Yau AC, Holmdahl R. Rheumatoid arthritis: identifying and characterising polymorphisms using rat models. Disease models \& mechanisms. 2016 Oct 1; 9(10):1111-23.
19. Williams RO. Models of rheumatoid arthritis. In Animal Models of T Cell-Mediated Skin Diseases 2005 (pp. 89-117). Springer, Berlin, Heidelberg.

20. Williams RO. Collagen-induced arthritis as a model for rheumatoid arthritis. In-Tumor Necrosis Factor 2004 (pp. 207-216).

21. www.chondrex,inc.

22. Vogel HG. Drug discovery and evaluation pharmacological assays. $2^{\text {nd }}$ edition. New York: Springer-Verlag Berlin Heidelberg; 2002. P.776-820.

23. Cremer MA, Rosloniec EF, Kang AH. The cartilage collagens: a review of their structure, organization, and role in the pathogenesis of experimental arthritis in animals and in human rheumatic disease. Journal of molecular medicine. 1998 Feb 1; 76(3-4):275-88.

24. Billiau A, Matthys P. Collagen-induced arthritis and related animal models: how much of their pathogenesis is autoimmune, how much is auto-inflammatory? Cytokine \& growth factor reviews. 2011 Oct 1; 22(5-6):339-44. 